\title{
System of multifunctional Jones matrix tomography of phase anisotropy in diagnostics of endometriosis
}

\author{
V.O. Ushenko ${ }^{a}$, G.D. Koval ${ }^{b}$, Yu. O. Ushenko ${ }^{a}$, L.Y. Pidkamin ${ }^{a}$, M.I. Sidor ${ }^{a}$, O. Vanchuliak ${ }^{b}$, \\ A.V. Motrich ${ }^{a}$, M.P. Gorsky ${ }^{a}$, I.Meglinskiy ${ }^{c}$, \\ ${ }^{a}$ Chernivtsi National University, 2 Kotsyubinsky Str., Chernivtsi, 58012, Ukraine \\ ${ }^{\mathrm{b}}$ Bukovinian State Medical University, Chernivtsi, 58000, Ukraine \\ ${ }^{\mathrm{c}}$ University of Oulu, P.O. Box 4500, Oulu, Finland
}

\begin{abstract}
The paper presents the results of Jones-matrix mapping of uterine wall histological sections with second-degree and third-degree endometriosis. The technique of experimental measurement of coordinate distributions of the modulus and phase values of Jones matrix elements is suggested. Within the statistical and cross-correlation approaches the modulus and phase maps of Jones matrix images of optically thin biological layers of polycrystalline films of plasma and cerebrospinal fluid are analyzed. A set of objective parameters (statistical and generalized correlation moments), which are the most sensitive to changes in the phase of anisotropy, associated with the features of polycrystalline structure of uterine wall histological sections with second-degree and third-degree endometriosis are determined.
\end{abstract}

Keywords: Jones matrix, tomography, phase anisotropy, diagnostics

\section{INTRODUCTION}

In recent years in the field of biomedical optics a new basic approach in a well-tested diagnostic direction has been formed - Mueller-matrix polarimetry of biological tissues ${ }^{1-13}$.

However, for non-depolarizing biological layers ${ }^{5,6,14-28}$ more appropriate to apply the Jones-matrix formalism.

Our work consists in the study of the modulus and phase distributions of the Jones-matrix elements characterizing the optically anisotropic structure of uterine wall histological sections with second-degree and third-degree endometriosis using the statistical and correlation approaches. The aim of the research is to determine the objective criteria that ensure reliable differentiation of such objects and can be treated as the basis for the development of Jones-matrix diagnostics of non-depolarizing biological layers.

\section{BRIEF THEORY}

It is obtained an analytical expression for the resulting Jones matrix of a phase anisotropic transparent layer by modeling as a sequence of linearly and circularly birefringent layers in ${ }^{18-28}$.

$$
\begin{gathered}
\{J\}=\left\|\begin{array}{ll}
j_{11} & j_{12} \\
j_{21} & j_{22}
\end{array}\right\|=\left\|\begin{array}{cc}
\cos U-i \frac{\delta \sin U}{2 U} & -\zeta \frac{\sin U}{U} \\
\zeta \frac{\sin U}{U} & \cos U+i \frac{\delta \sin U}{2 U}
\end{array}\right\| . \\
U^{2}=N^{2} \theta^{2}=\zeta^{2}+\left(\frac{\delta}{2}\right)^{2} .
\end{gathered}
$$

Expression (1) is an accurate analytical record of Jones-matrix elements of an optically anisotropic layer with linear $(\delta)$ and circular $(\zeta)$ birefringence.

In the approximation of weak phase fluctuations (1) can be rewritten as follows 


$$
\left\|\begin{array}{ll}
j_{11} & j_{12} \\
j_{21} & j_{22}
\end{array}\right\|=\| \begin{array}{cc}
\left.\left(1+\zeta^{2}\right)-i \delta\right]_{11} & {[2 \zeta+i \zeta \delta]_{12}} \\
2 \zeta+i \zeta \delta]_{21} & {\left[\left(1+\zeta^{2}\right)+i \delta\right]_{22}}
\end{array} \mid .
$$

From Jones matrix (3) we obtain the analytical expressions for linear $(\delta)$ and circular $(\zeta)$ birefringence

$$
\begin{gathered}
\delta=2 \operatorname{tg} \operatorname{Arg}\left(j_{12 ; 21}\right) . \\
\zeta=\sqrt{1-0,5 \frac{\operatorname{tg}\left(\operatorname{Arg}\left(j_{12 ; 21}\right)\right)}{\operatorname{tg}\left(\operatorname{Arg}\left(j_{11 ; 22}\right)\right)} .} .
\end{gathered}
$$

Measurements of the elements of Jones matrix distributions were carried out according to the classical technique presented in ${ }^{16}$.

\section{ANALYSIS AND DISCUSSION OF EXPERIMENTAL DATA}

Two groups of histological sections of the endometriosis uterine wall second-degree (sample 31 - group 1) and thirddegree (sample 31) were studied.

The series of Fig. 1 - Fig. 4 represent maps (fragments 1), histograms (fragments (2)), autocorrelation functions (fragments (3)) and logarithmic dependences of power spectra (fragments (4)) extreme values distributions of Linear $(\delta$ ) and circular $(\zeta)$ birefringence of the group 1 (Figure 1, Figure 3) endometrium histological sections and group 2 (Fig. 2, Fig. 4).

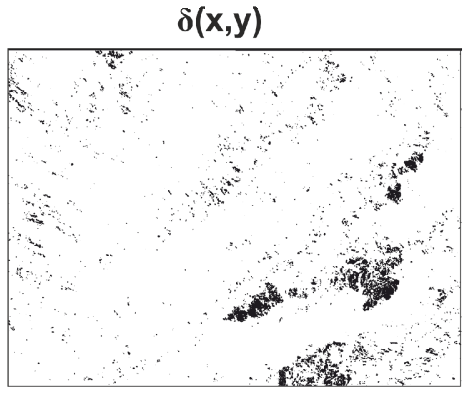

(1)

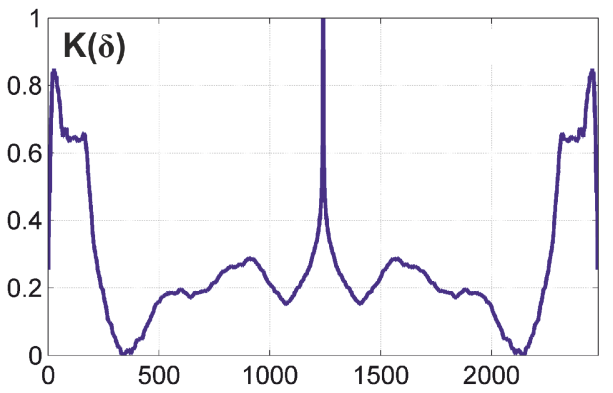

(3)

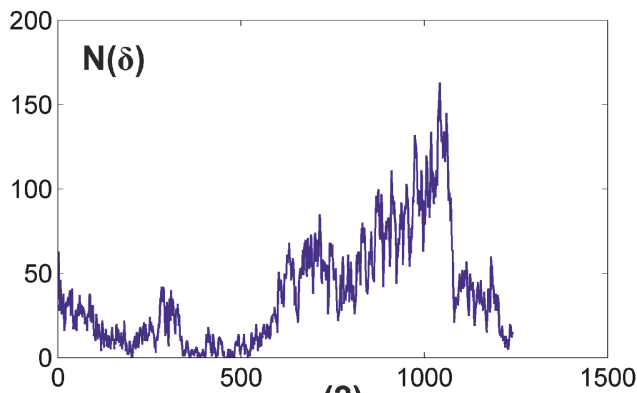

(2)

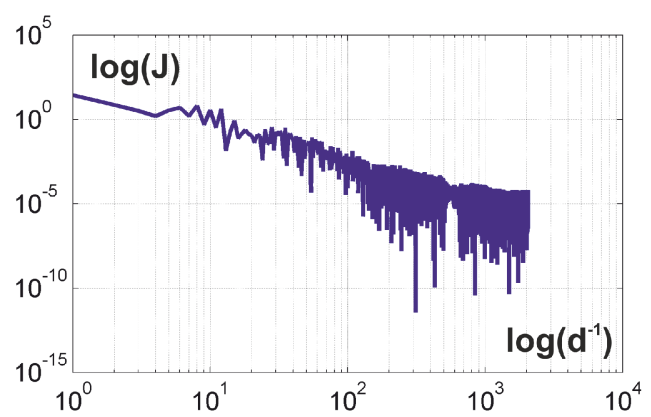

(4)

Figure 1. Statistical, correlation and fractal parameters of the group 1 of endometrium sample linear birefringence distributions. 


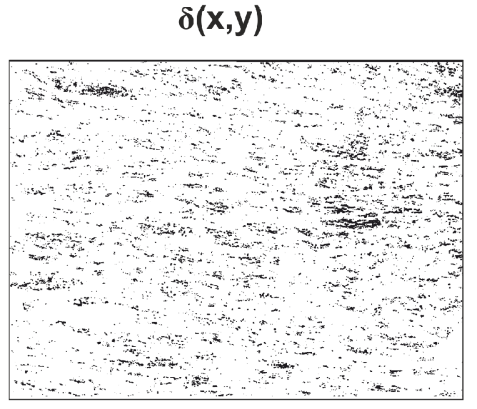

(1)

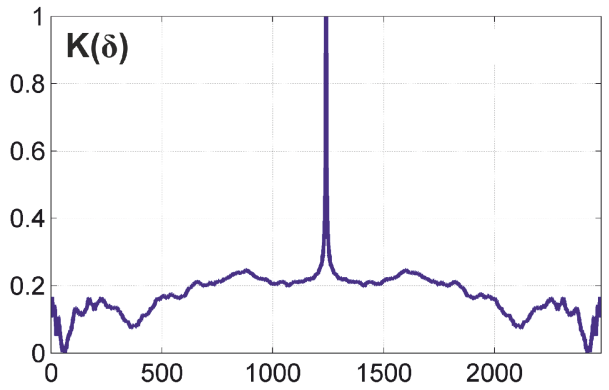

(3)

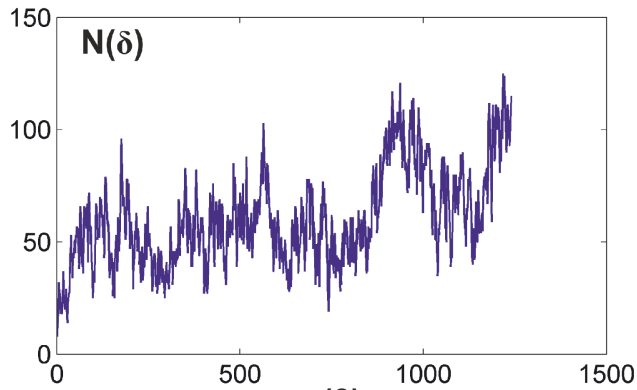

(2)

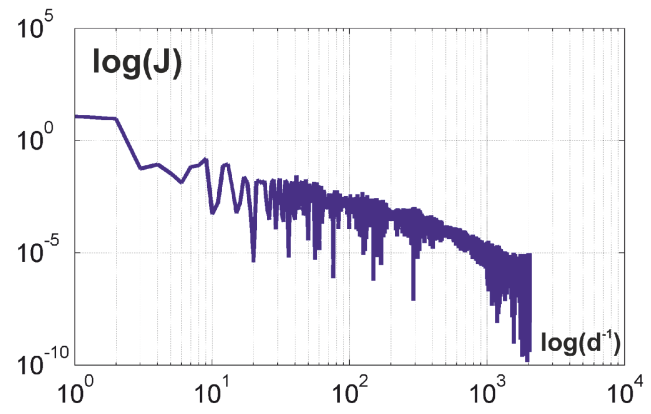

(4)

Figure 2. Statistical, correlation and fractal parameters of the group 2 of endometrium sample linear birefringence distributions.

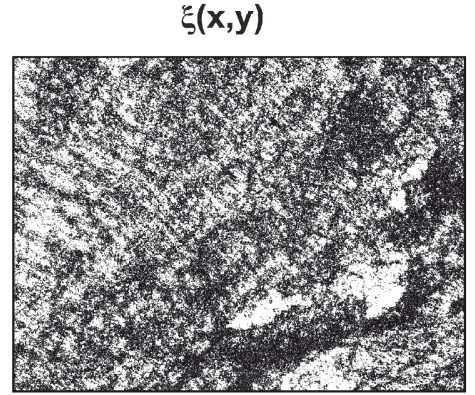

(1)

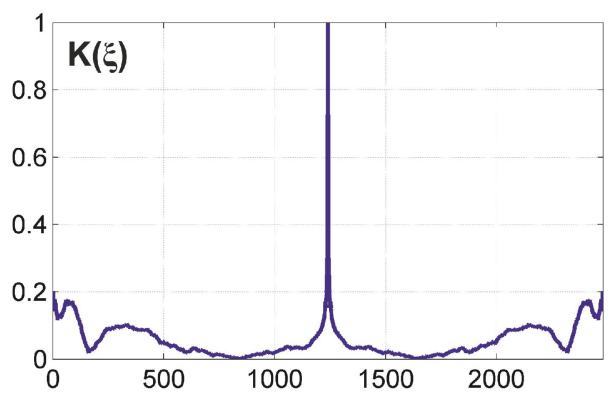

(3)

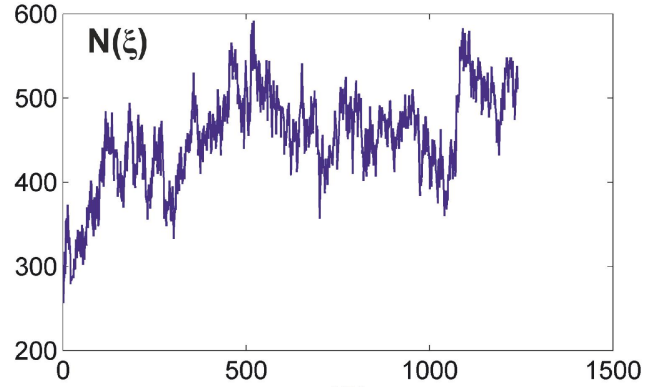

(2)

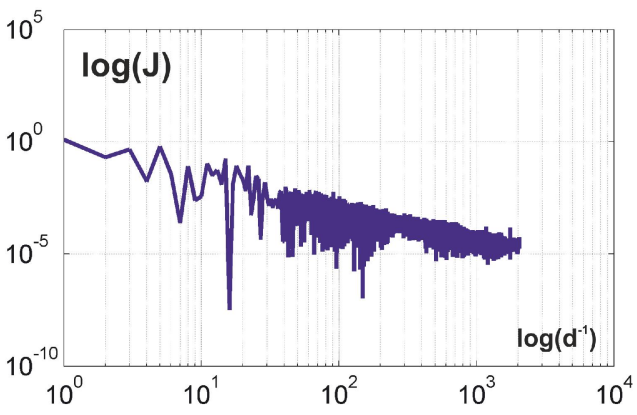

(4)

Figure 3. Statistical, correlation and fractal parameters of the group 1 of endometrium sample circular birefringence distributions. 


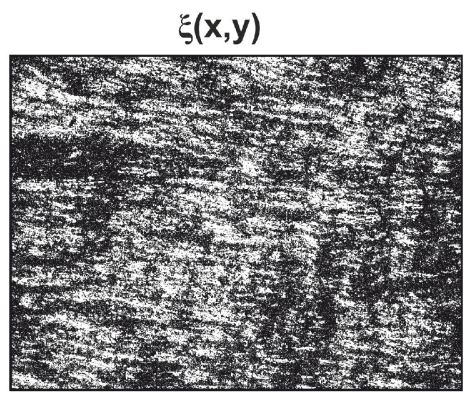

(1)

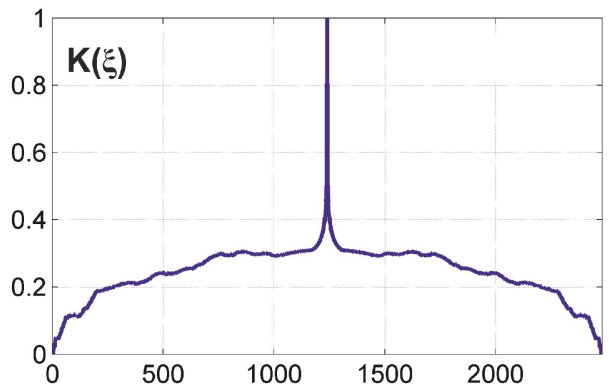

(3)

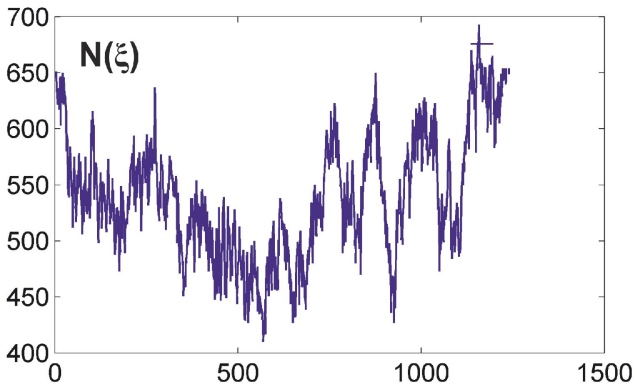

(2)

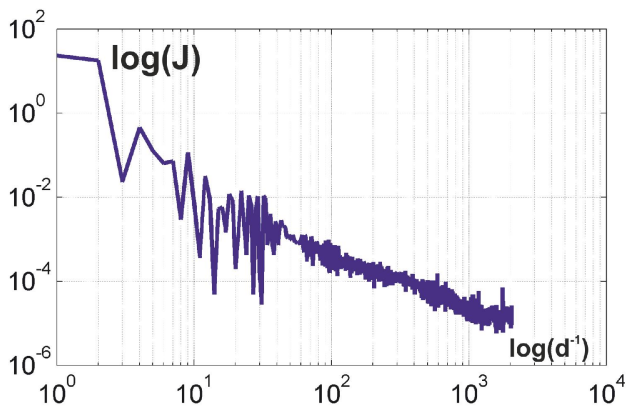

(4)

Figure 4. Statistical, correlation and fractal parameters of the group 2 of endometrium sample circular birefringence distributions.

In order to identify the sensitivity of the Jones matrix method of planar polycrystalline non-depolarizing layers mapping to changes of linear and circular birefringence the results obtained (Fig. 1 - Fig. 4) were compared by determining the set of statistical (statistical moments of the 1st - 4th orders ${ }^{14}$ ), correlation (correlation moments 2 nd and 4th orders ${ }^{15}$ ) and fractal ${ }^{16}$ parameters that characterize the distribution $\delta$ и $\zeta$-Table 1.

Table 1. Statistical, correlation and fractal moments of linear and circular birefringence distributions

\begin{tabular}{|c|c|c|c|c|}
\hline \multirow{2}{*}{$Z_{i}$} & \multicolumn{2}{|c|}{ Group 1 } & \multicolumn{2}{c|}{ Group 2 } \\
\cline { 2 - 5 } & $\delta$ & $\zeta$ & $\delta$ & $\zeta$ \\
\hline$Z_{1}$ & 0,055 & 0,06 & 0,029 & 0,052 \\
\hline$Z_{2}$ & 0,029 & 0,08 & 0,017 & 0,06 \\
\hline$Z_{3}$ & 0,22 & 1,52 & 0,02 & 1,23 \\
\hline$Z_{4}$ & 1,35 & 3,17 & 0,77 & 1,94 \\
\hline$Z^{k}{ }_{2}$ & 0.11 & 0.008 & 0.14 & 0,12 \\
\hline$Z_{4}^{k}$ & 1.88 & 2.44 & 1.02 & 3.89 \\
\hline$D_{f}$ & 0.19 & 0.25 & 0.23 & 0,33 \\
\hline
\end{tabular}

The comparative analysis of data presented in Table 1 showed diagnostic sensitivity of a number of objective parameters:

$$
\Delta Z_{4}(\delta)=2,05
$$

$\Delta Z_{4}(\zeta)=1,86$ 


$$
\begin{aligned}
& \Delta \mathrm{Z}_{4}^{k}(\delta)=1,79 \\
& \Delta \mathrm{Z}_{4}^{k}(\zeta)=1,66 \\
& \Delta D_{f}(\delta)=1,55 \\
& \Delta D_{f}(\zeta)=1,63
\end{aligned}
$$

\section{CONCLUSION}

The Jones matrix model of differentiating the weak changes of phase anisotropy of the endometrium histological sections with different pathologies is suggested.

The coordinate distributions of the endometrium tissues linear and circular birefringence are experimentally determined. Within the statistical, correlation and fractal analysis of coordinate distributions of linear and circular birefringence the objective parameters are determined that are most sensitive (statistical moments of the 3rd and 4th orders, generalized correlation moment of the 4th order) to changes of the phase anisotropy of optically thin endometrium biological tissue of different endometriosis pathology.

\section{REFERENCES}

[1] Müller G. et al., Eds., [Medical Optical Tomography: Functional Imaging and Monitoring] Vol. IS11, SPIE Press, Bellingham, Washington (1993).

[2] Wang L. V. and Wu H.-I., [Biomedical Optics: Principles and Imaging], Wiley-Interscience, Hoboken, New Jersey (2007).

[3] Boas D., Pitris C., and Ramanujam N., Eds., [Handbook of Biomedical Optics], CRC Press, Boca Raton, London, New York (2011).

[4] Vo-Dinh T., Ed., [Biomedical Photonics Handbook], 2nd ed., CRC Press, Boca Raton (2014).

[5] Tuchin V. V., [Tissue Optics: Light Scattering Methods and Instruments for Medical Diagnostics], 3rd ed., Vol. PM254, SPIE Press, Bellingham, Washington (2015).

[6] Ghosh N.and Vitkin I. A., "Tissue polarimetry: concepts, challenges, applications and outlook," J. Biomed. Opt. 16, 110801 (2011).

[7] Wu P. J. and J. T. Walsh Jr., "Stokes polarimetry imaging of rat tail tissue in a turbid medium: degree of linear polarization image maps using incident linearly polarized light" J. Biomed. Opt. 11, 014031 (2006).

[8] Shukla P. and Pradhan A., "Mueller decomposition images for cervical tissue: potential for discriminating normal and dysplastic state" Opt. Express 17, 1600-1609 (2009).

[9] Li X.and Yao G., "Mueller matrix decomposition of diffuse reflectance imaging in skeletal muscle," Appl. Opt. 48, 2625-2631 (2009).

[10] Angelsky, O. V., Gorsky, M. P., Hanson, S. G., Lukin, V. P., Mokhun, I. I., Polyanskii, P. V., Ryabiy, P. A., "Optical correlation algorithm for reconstructing phase skeleton of complex optical fields for solving the phase problem," Opt. Exp. 22(5), 6186-6193 (2014).

[11] Du E. et al., "Mueller matrix polarimetry for differentiating characteristic features of cancerous tissues," J. Biomed. Opt. 19(7), 076013 (2014).

[12] Angelsky, O.V., Hanson, S.G., Maksimyak, P.P., Maksimyak, A.P., Zenkova, C.Yu., Polyanskii, P.V., Ivanskyi, D.I., "Influence of evanescent wave on birefringent microplates," Opt. Express 25, 2299-2311 (2017).

[13] Angelsky, O. V., Bekshaev, A. Ya., Maksimyak, P. P., Maksimyak, A. P., Hanson, S. G., Kontush, S. M., "Controllable generation and manipulation of micro-bubbles in water with absorptive colloid particles by $\mathrm{CW}$ laser radiation," Opt. Express 25, 5232-5243 (2017).

[14] Ushenko V. A., Gavrylyak M. S., "Azimuthally invariant Mueller-matrix mapping of biological tissue in differential diagnosis of mechanisms protein molecules networks anisotropy" Proc. SPIE 8812, Biosensing and Nanomedicine VI, 88120Y (2013).

[15] Ushenko V. A., Gorsky M. P., "Complex degree of mutual anisotropy of linear birefringence and optical activity of biological tissues in diagnostics of prostate cancer" Optics and Spectroscopy, 115(2), 290-297 (2013). 
[16] Ushenko Y.A., Boychuk T.M., Bachynsky V.T. and Mincer O.P., [Diagnostics of Structure and Physiological State of Birefringent Biological Tissues: Statistical, Correlation and Topological Approaches], Handbook of Coherent-Domain Optical Methods, 107-148 (2013).

[17] Angelsky, O. V., Bekshaev, A. Ya., Maksimyak, P. P., Maksimyak, A. P., Hanson, S. G., Zenkova, C. Yu., "Self-diffraction of continuous laser radiation in a disperse medium with absorbing particles," Optics Express 21(7), 8922-8938, (2013).

[18] Angelsky, O. V., Bekshaev, A. Ya., Maksimyak, P. P., Maksimyak, A. P., Hanson, S. G., Zenkova, C. Yu., "Self-action of continuous laser radiation and Pearcey diffraction in a water suspension with light-absorbing particles," Optics Express 22(3), 2267-2277, (2014).

[19] Ushenko V. A., Zabolotna N. I., Pavlov S. V., Burcovets D. M. and Novakovska O. Yu., "Mueller-matrices polarization selection of two-dimensional linear and circular birefringence images," Proc.SPIE 9066, (2013).

[20] Ushenko V. A., Dubolazov A. V., "Correlation and self similarity structure of polycrystalline network biological layers Mueller matrices images," Proc. SPIE 8856, (2013).

[21] Ushenko Yu. A., Ushenko V. A., Dubolazov A. V., Balanetskaya V. O. and Zabolotna N. I., "Mueller-matrix diagnostics of optical properties of polycrystalline networks of human blood plasma" Optics and Spectroscopy 112(6), 884-892 (2012).

[22] Ushenko Yu. A., Dubolazov A. V., Balanetskaya V. O., Karachevtsev A. O. and Ushenko V. A., "Waveletanalysis of polarization maps of human blood plasma," Optics and Spectroscopy, 113(3), 332-343. (2012).

[23] Angelsky, O.V., Tomka, Y.Y., Ushenko, A.G., Ushenko, Y.G., Yermolenko, S.B., "2-D tomography of biotissue images in pre-clinic diagnostics of their pre-cancer states," Proc. SPIE., 5972, 158-162, (2005).

[24] Angelsky, O.V., Besaha, R.N., Mokhun, A.I., Mokhun, I.I., Sopin, M.O., Soskin, M.S., "Singularities in vectoral fields," Proc. SPIE, 40-54, (1999).

[25] Polyanskii, V.K., Angelsky, O.V., Polyanskii, P.V., "Scattering-induced spectral changes as a singular optical effect," Optica Applicata 32 (4), 843-848, (2002).

[26] Ungurian V. P., Ivashchuk O. I., Ushenko V. O., "Statistical analysis of polarizing maps of blood plasma laser images for the diagnostics of malignant formations," Proc. SPIE 8338, 83381L (2011).

[27] Ushenko V. A., Dubolazov O. V., Karachevtsev A. O., "Two wavelength Mueller matrix reconstruction of blood plasma films polycrystalline structure in diagnostics of breast cancer," Applied Optics. 53(10), B128B139 (2014).

[28] Prysyazhnyuk V. P., Ushenko Yu. A., Dubolazov A. V., Ushenko A. G. and Ushenko V. A., "Polarizationdependent laser autofluorescence of the polycrystalline networks of blood plasma films in the task of liver pathology differentiation," Appl. Opt. 55, B126-B132 (2016). 